\title{
Sintering of magnesia: effect of additives
}

\author{
SATYANANDA BEHERA and RITWIK SARKAR* \\ Department of Ceramic Engineering, National Institute of Technology, Rourkela 769008, India
}

MS received 15 April 2015; accepted 4 June 2015

\begin{abstract}
Effect of different additives, namely $\mathrm{Cr}_{2} \mathrm{O}_{3}, \mathrm{Fe}_{2} \mathrm{O}_{3}$ and $\mathrm{TiO}_{2}$, up to 2 wt $\%$ was studied on the sintering and microstructural developments of the chemically pure magnesia using the pressureless sintering technique between 1500 and $1600^{\circ} \mathrm{C}$. Sintering was evaluated by per cent densification and microstructural developments were studied by electron microscopy and elemental distribution of the additives in the sintered products was also investigated for their distribution in the matrix. $\mathrm{Cr}_{2} \mathrm{O}_{3}$ and $\mathrm{TiO}_{2}$ were found to deteriorate the densification associated with grain growth. $\mathrm{Fe}_{2} \mathrm{O}_{3}$ was found to improve the densification and well-compacted grain distribution was observed in the microstructure.
\end{abstract}

Keywords. Magnesia; additives; sintering; densification; microstructure.

\section{Introduction}

Densification/sintering of a material is of high interest for ceramists due to increased density values and associated strength at temperatures without the generation of a considerable amount of the liquid phase. ${ }^{1}$ The term sintering, as used in ceramics, refers to the process by which an assembly of discrete particles is transformed into a single porous solid mass by the application of heat without liquefaction. ${ }^{2}$ At the microscopic level, the driving forces for sintering in the capillary pressure are associated with surface curve where particles come into contact. The neck formation between particles has a saddle curvature characterized by two radius of curvature $x$, the diameter of the neck and $\gamma$, which is small and negative. The capillary pressure is $\Delta p=\gamma(1 / \gamma+1 / x)$ and is negative ( $\gamma=$ surface energy). Summed over powder compact, the capillary pressure gives a modest net compressive pressure in sintering. ${ }^{3}$

In ceramics, magnesia is a valuable material, mostly useful as a refractory with a high resistivity against alkali metals and basic environments. Magnesia is important refractory material for cement rotary kilns, steel ladle, converters and furnaces, due to the higher softening temperature of $\mathrm{MgO}$ $\left(2800^{\circ} \mathrm{C}\right)$ and also because of its chemical stability in a basic environment. ${ }^{4}$ However, they do have shortcomings such as lower thermal shock resistance as well as higher thermal conductivity, which limits their applications. ${ }^{1}$ To improve corrosion, especially infiltration resistance, the effect of different additives, such as $\mathrm{SiO}_{2}, \mathrm{Cr}_{2} \mathrm{O}_{3}, \mathrm{Al}_{2} \mathrm{O}_{3}, \mathrm{TiO}_{2}, \mathrm{MgCl}_{2}, \mathrm{WO}_{3}$ and $\mathrm{ZrO}_{2}$ were studied since long. ${ }^{1,5-12}$ Even small additions (less than 1\%) of other materials have a marked effect

*Author for correspondence (ritwiksarkar@ rediffmail.com) on the grain growth, densification, and other properties. ${ }^{13}$ The method of preparation of magnesia ${ }^{14}$ was reported to be important for sintering and calcination of magnesium carbonate resulting in magnesia was found to be easily sintered at temperature as low as $1650^{\circ} \mathrm{C}$. Very high relative density ( $\sim 98.8 \%$ ) of sintered magnesia was reported ${ }^{15}$ with restrained grain growth at $1740 \mathrm{~K}$ by using ultra-high heating rate (above $1700 \mathrm{~K} \mathrm{~min}^{-1}$ ) under an applied pressure of up to $170 \mathrm{MPa}$. Grain growth of the nanocrystalline $\mathrm{MgO}$ was reported to be controlled by the mechanism of evaporationcondensation rather than surface diffusion. Applied pressure was reported ${ }^{16}$ to have a result of increasing densification while restraining grain growth, and the higher sintering temperature was reported to result in larger grain size as well as lower density. Pure magnesia with a relative density of $99.1 \%$ nanocrystalline ceramics was obtained at $1620 \mathrm{~K}$ and 170 $\mathrm{MPa}$, and simultaneously grain growth was almost quietly restrained.

Literature shows the effect of various additives on densification of magnesia. For example, Weyl ${ }^{17}$ discussed the behaviour of foreign ions in a crystal lattice and Tacvorian ${ }^{18}$ studied the problem that arises due to the phase diagram and liquid phase formation from the macroscopic point of view. Nelson and Culter ${ }^{10}$ studied the effect of many additives in the range of $1-16 \%$. Additions of $\mathrm{Ti}^{4+}, \mathrm{Al}^{3+}, \mathrm{Cr}^{3+}, \mathrm{Mn}^{2+}$ and $\mathrm{Fe}^{3+}$ were found to be successful in decreasing the sintering temperature of magnesia due to non-stoichiometry of periclase caused by crystal lattice defects. ${ }^{19,20}$ The addition of $\mathrm{ZrO}_{2}$ in $\mathrm{MgO}$ was reported ${ }^{21}$ to enhance the densification and the main reasons proposed were the conversion of monoclinic $\mathrm{ZrO}_{2}$ to its cubic phase $\mathrm{ZrO}_{2}$. Also, excess $\mathrm{ZrO}_{2}$ was reported to react with $\mathrm{MgO}$ to form $\mathrm{Mg}_{0.13} \mathrm{Zr}_{0.87} \mathrm{O}_{1.87}$, which activated lattice and promoted the diffusion of ions during the sintering process. In addition, liquid phase sintering was also one of the main reasons for promoting the sintering of 
magnesia. Dense $\mathrm{MgO}$ was prepared by adding $\mathrm{TiO}_{2}$ due to cation vacancy formation as follows: ${ }^{22}$

$$
\mathrm{TiO}_{2} \stackrel{\mathrm{MgO}}{\longrightarrow} \mathrm{Ti}_{\mathrm{Mg} \bullet \bullet}+\mathrm{V}_{\mathrm{Mg}^{\prime \prime}}+2 \mathrm{O}_{\mathrm{o}}
$$

A prominent adequate grain growth is observed due to the addition of $\mathrm{TiO}_{2}$ on densification and at relatively low

Table 1. Ionic radius of various cations (pico-metre). ${ }^{26,27}$

\begin{tabular}{lccc}
\hline $\mathrm{Mg}^{2+}$ & $\mathrm{Ti}^{4+}$ & $\mathrm{Fe}^{3+}$ & $\mathrm{Cr}^{3+}$ \\
\hline 72 & 61 & 64.5 & 62 \\
\hline
\end{tabular}

temperatures $<1500^{\circ} \mathrm{C}$ and $\mathrm{TiO}_{2}$ content up to $5 \mathrm{wt} \% .^{12}$ Even $(0.5 \%)$ of $\mathrm{TiO}_{2}$ is favourable to enhance the densification of magnesia even at $1300^{\circ} \mathrm{C} .{ }^{11}$ The addition of $\mathrm{TiO}_{2}$, exceeding solid solubility limit, results in the intergranular and intragranular magnesium titanate $\left(\mathrm{Mg}_{2} \mathrm{TiO}_{4}\right)$ formation, which promotes magnesia grain growth. ${ }^{20,23}$ The addition of $\mathrm{TiO}_{2}$ was also reported ${ }^{24}$ to decrease the activation energy of $\mathrm{MgO}$ grain growth, accelerated the growth rate of $\mathrm{MgO}$ grains, and markedly promoted the sintering of $\mathrm{MgO}$, prepared from $\mathrm{MgCl}_{2} \cdot 6 \mathrm{H}_{2} \mathrm{O}$. The principal mechanism of $\mathrm{TiO}_{2}$ promoting the sintering of $\mathrm{MgO}$ was that $\mathrm{TiO}_{2}$ solubilized in $\mathrm{MgO}$ to form unequivalence substitutional solid solutions and cation vacancies that were favourable to cation diffusion.

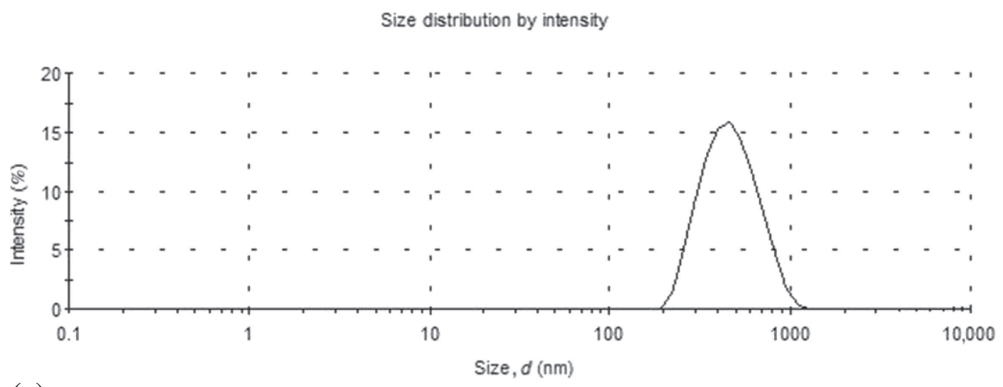

(a)

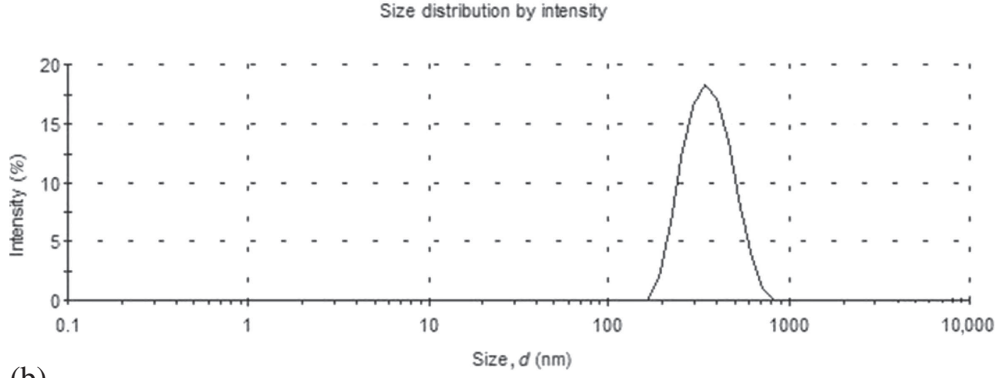

(b)

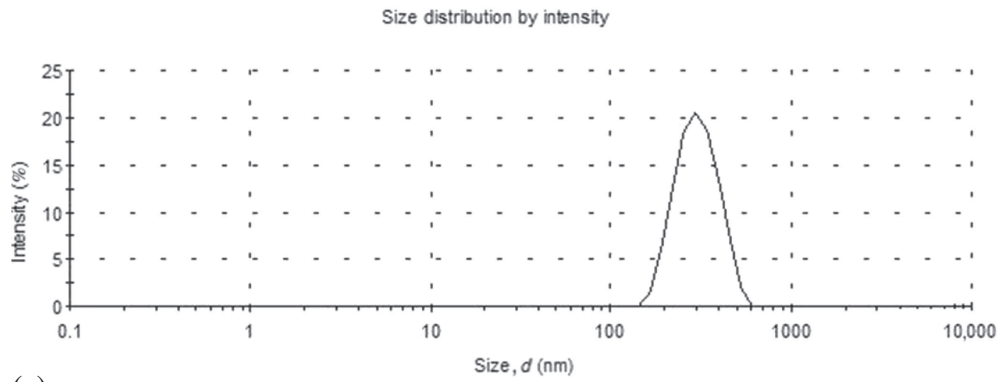

(c)

Size distribution by intensity

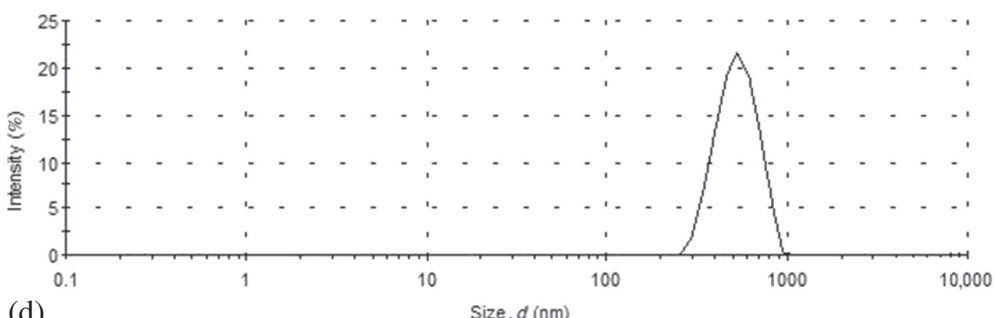

(d)

Size, $d(\mathrm{~nm})$

Figure 1. Particle size distribution of (a) $\mathrm{MgO}$, (b) $\mathrm{TiO}_{2}$, (c) $\mathrm{Cr}_{2} \mathrm{O}_{3}$ and (d) $\mathrm{Fe}_{2} \mathrm{O}_{3}$ particles. 
Reduction in the size of the $\mathrm{Cr}_{2} \mathrm{O}_{3}$ additive was found to be more efficient and beneficial for densification of magnesia. ${ }^{25}$ According to the phase analysis, higher dissolution of $\mathrm{Cr}_{2} \mathrm{O}_{3}$ in the $\mathrm{MgO}-\mathrm{Cr}_{2} \mathrm{O}_{3}$ system was also responsible for the faster densification. ${ }^{25}$ The addition of iron in magnesia also promotes low-temperature densification that appears to be proportional to the degree of solid solution and arising vacancies. $^{7}$

In the present work, densification and microstructural characterization of magnesia is studied at pressureless sintering condition in the presence of different additives like $\mathrm{Cr}_{2} \mathrm{O}_{3}$, $\mathrm{Fe}_{2} \mathrm{O}_{3}$ and $\mathrm{TiO}_{2}$. The additives were chosen to have very

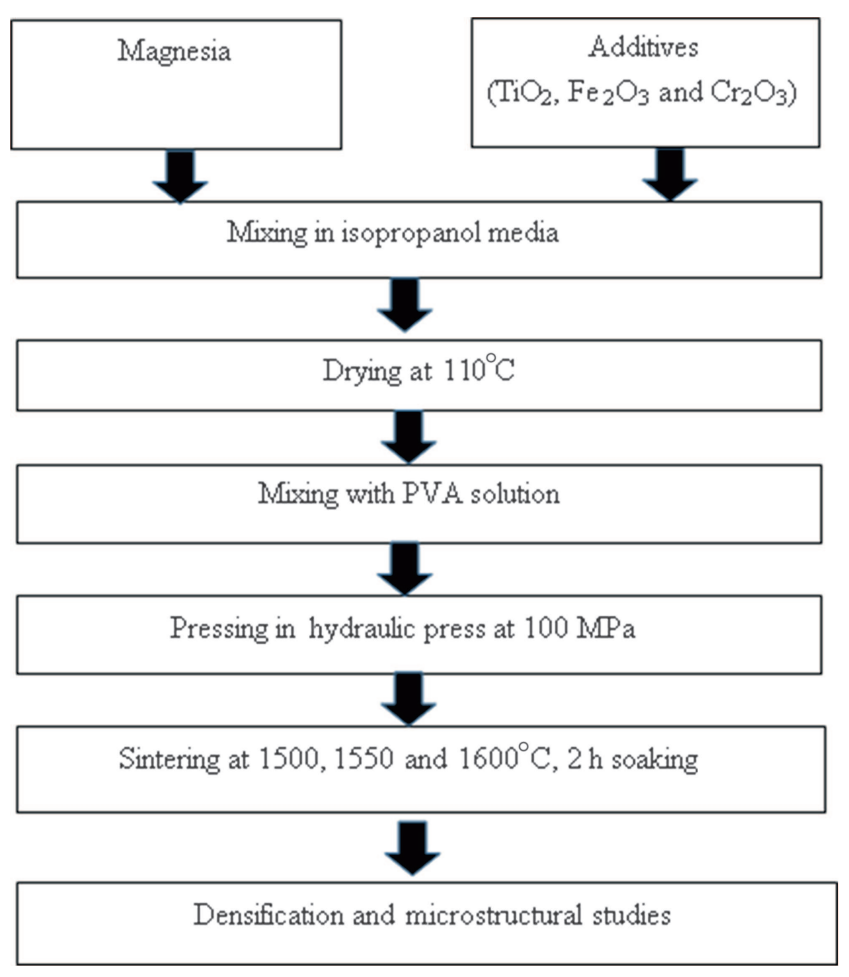

Figure 2. Process flow diagram.

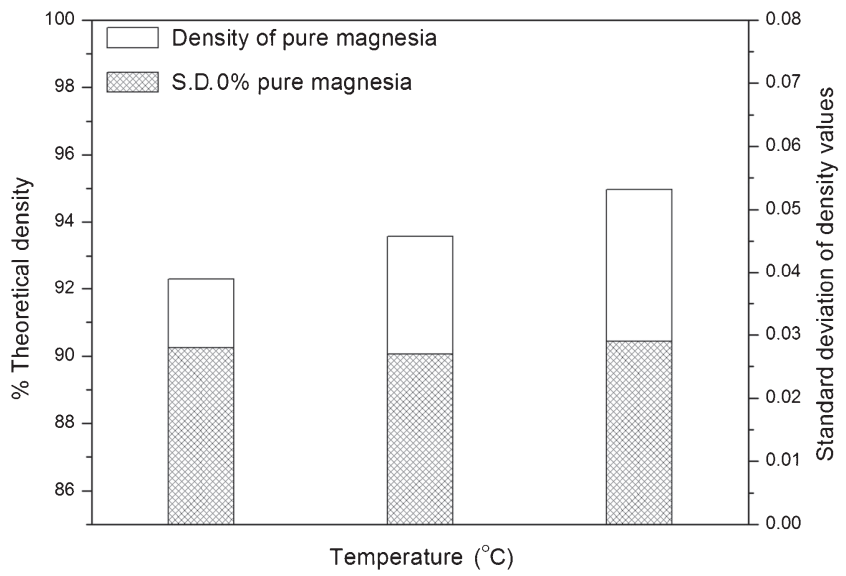

Figure 3. Variation in density and standard deviation of density values of pure $\mathrm{MgO}$ composition against temperature. close cationic radius compared to that of magnesium ion, which may help in faster solid solution formation. Table 1
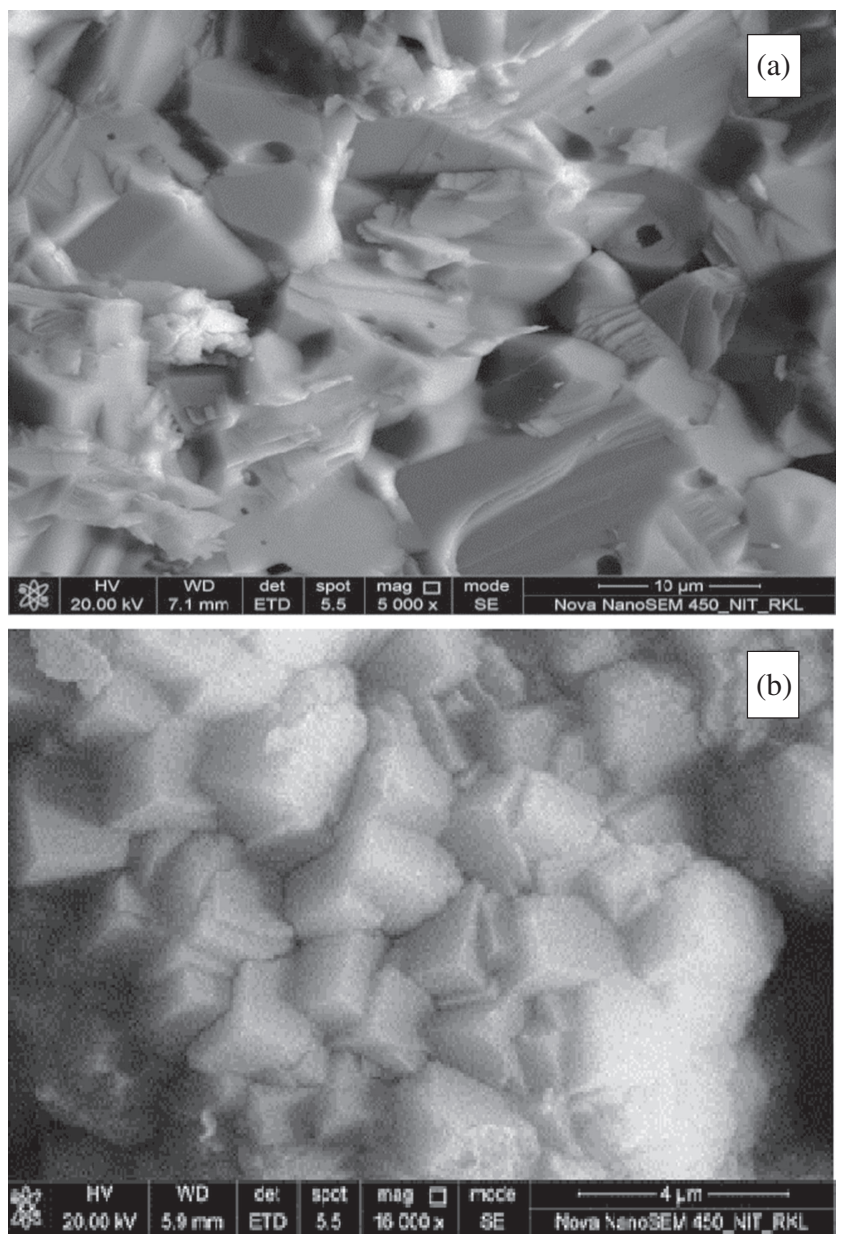

Figure 4. (a and b) Scanning electron photomicrograph of fractured surface of pure magnesia batch sintered at $1600^{\circ} \mathrm{C}$ (no additive).

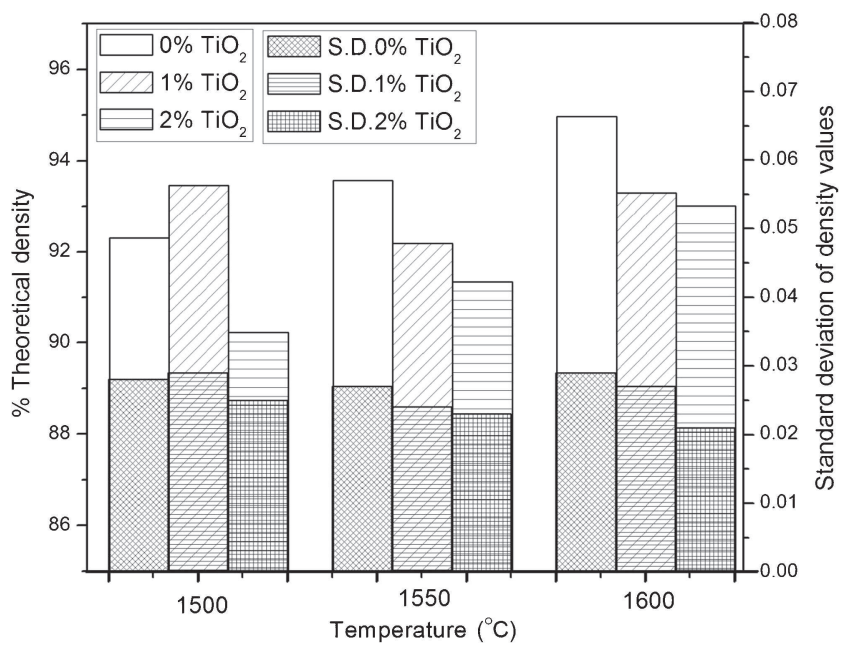

Figure 5. Variation in density and standard deviation of density values of $\mathrm{MgO}$ containing $\mathrm{TiO}_{2}$ additives. 
provides the ionic radius of various cations used in the study. ${ }^{26,27}$

\section{Experimental}

High-purity chemical grade magnesia (LobaChemie, India, AR grade, purity >99) was taken for the study. Different additives namely, $\mathrm{TiO}_{2}, \mathrm{Cr}_{2} \mathrm{O}_{3}$ and $\mathrm{Fe}_{2} \mathrm{O}_{3}$ (LobaChemie, India, Purity >97\%) were used at 1 and $2 \mathrm{wt} \%$. The particle size distributions of $\mathrm{MgO}$ as well as the additives, $\mathrm{TiO}_{2}$, $\mathrm{Cr}_{2} \mathrm{O}_{3}$ and $\mathrm{Fe}_{2} \mathrm{O}_{3}$, are given in figure $1 \mathrm{a}-\mathrm{d}$, respectively. All

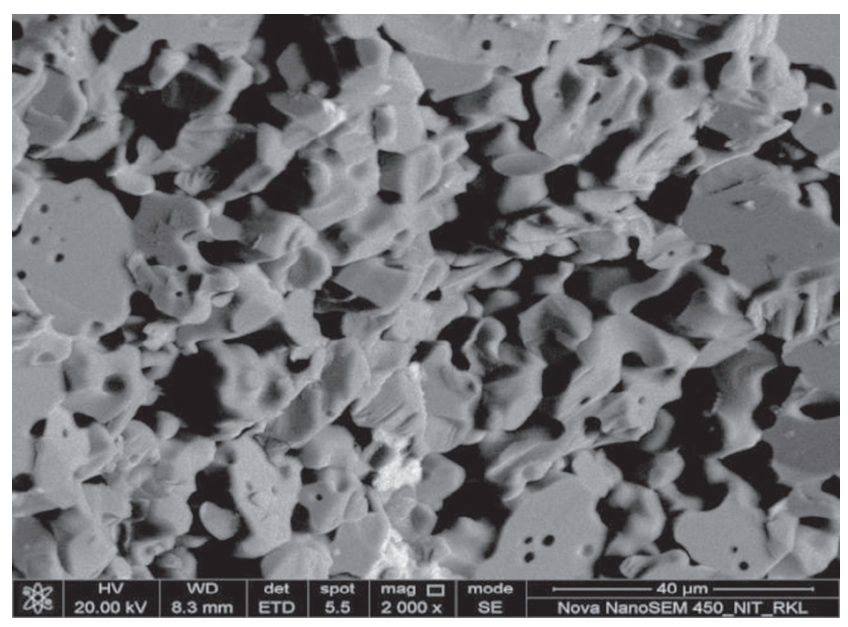

Figure 6. Scanning electron photomicrograph of the fractured surface of $2 \mathrm{wt} \% \mathrm{TiO}_{2}$ containing magnesia batch sintered at $1600^{\circ} \mathrm{C}$. the different batches were wet mixed in isopropanol medium using a magnetic stirrer and then dried at $110^{\circ} \mathrm{C}$. After this, all the different batches were pressed into pellets of $20 \mathrm{~mm}$ diameter in a uni-axial hydraulic press at $100 \mathrm{MPa}$ using $6 \%$ PVA solution (4 wt \% concentration) as green binder. Pressed samples were then oven dried at $110^{\circ} \mathrm{C}$ and sintered at 1500 , 1550 and $1600^{\circ} \mathrm{C}$ with soaking time of $2 \mathrm{~h}$. Fired products were then characterized for densification and microstructural studies.

Densification studies were conducted by the conventional liquid displacement method using the Archimedes principle in vacuum process with xylene as a liquid medium. Per cent theoretical (relative) density was calculated as a ratio of measured bulk density value with the theoretical density value. Each individual data represented in the study is an average of five individual samples and the variations of the individual values are represented as the standard deviation of the density values in the same densification plots. Particle size distribution of the starting materials was carried out in computer-controlled particle size analyser, Malvern Master Sizer (UK). Microstructural studies and elemental distribution were investigated in a field-emission scanning electron microscope (FEI, USA, make) attached with EDXA facility (Oxford, UK). The flow diagram of the process is given in figure 2 .

\section{Result and discussion}

Particle size distribution of high pure chemical grade magnesia and other additives are shown in figure 1. Magnesia
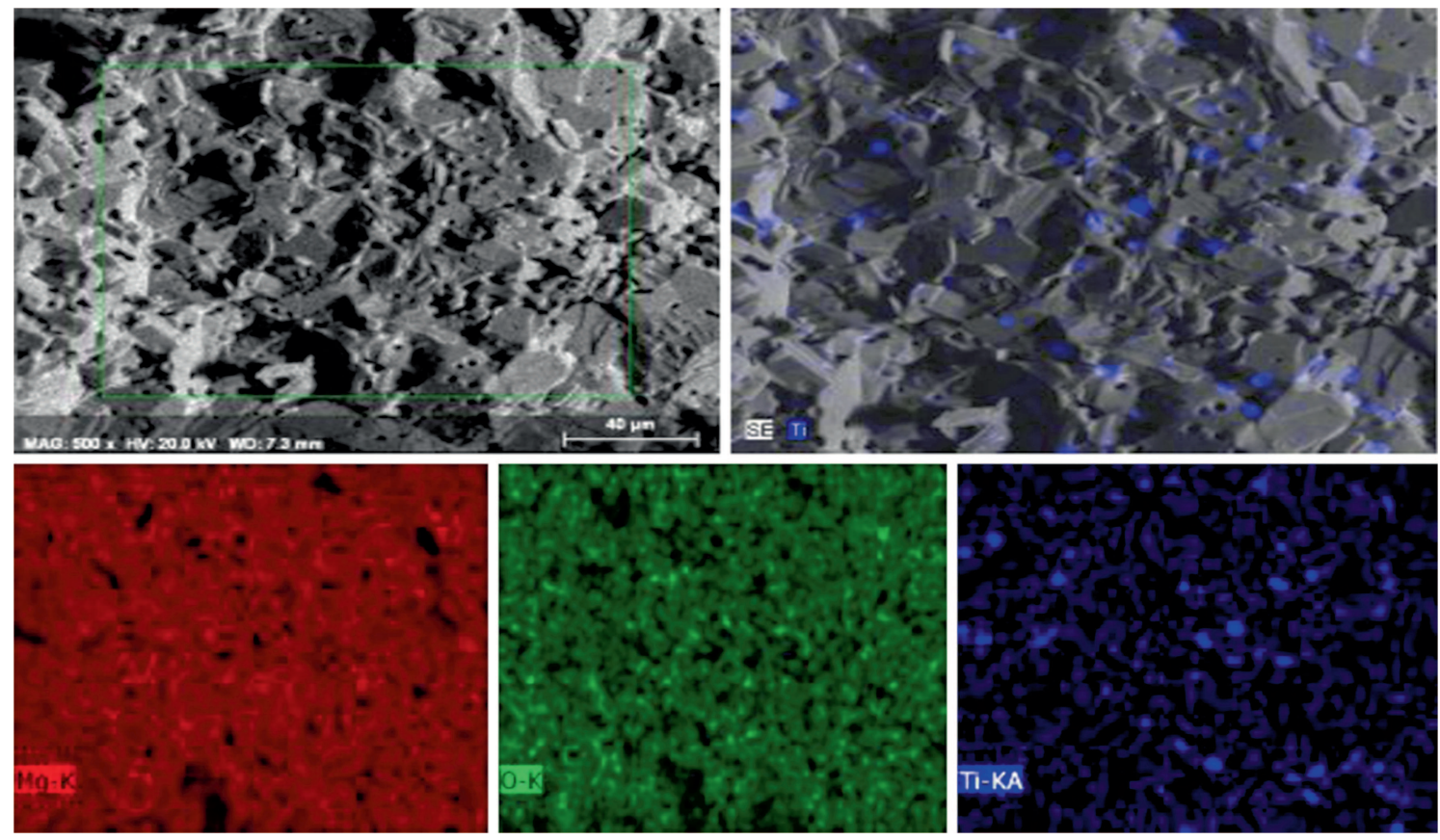

Figure 7. Elemental mapping photomicrograph of $2 \mathrm{wt} \% \mathrm{TiO}_{2}$ containing $\mathrm{MgO}$ sintered at $1600^{\circ} \mathrm{C}$. 


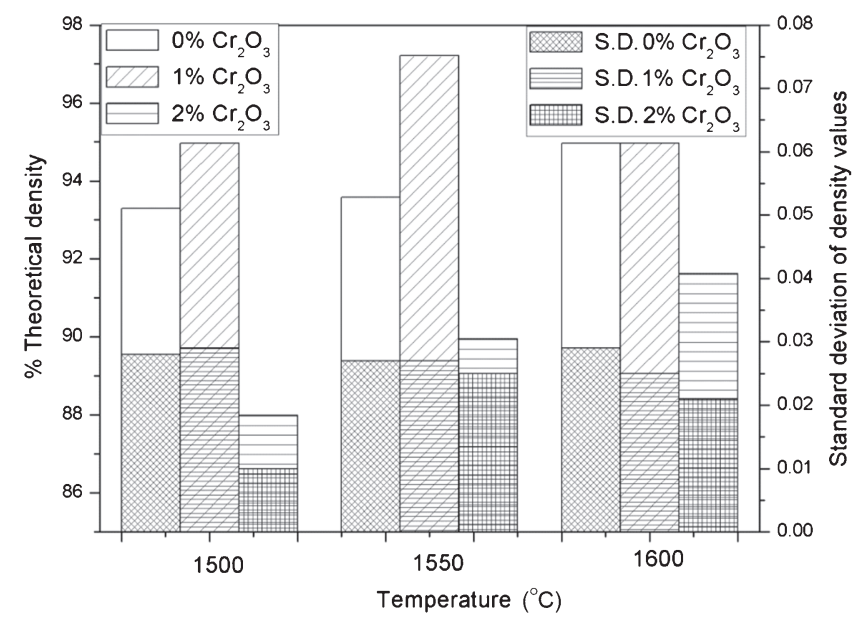

Figure 8. Variation in density and standard deviation of density values of $\mathrm{MgO}$ containing $\mathrm{Cr}_{2} \mathrm{O}_{3}$ additives.

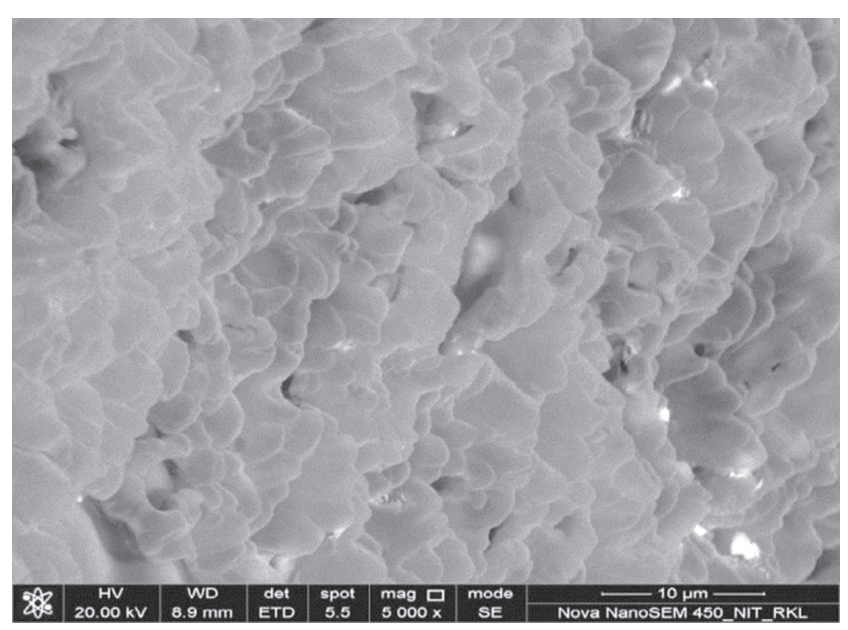

Figure 9. Scanning electron photomicrograph of the fractured surface of 1 wt $\% \mathrm{Cr}_{2} \mathrm{O}_{3}$ containing magnesia batch sintered at $1600^{\circ} \mathrm{C}$.

is a high pure $(>99 \%)$ fine powder with an average particle size of $450 \mathrm{~nm}$ (figure 1a). The additives used in the study are also highly pure and fine, having average particle size in the range of $300-600 \mathrm{~nm}$, details of the particle size distribution are provided in figure $1 \mathrm{~b}-\mathrm{d}$. Figure 3 shows the densification behaviour of pure magnesia containing no additive. Densification plot shows that the increase in temperature results in increased density values. Variations of the density values of individual samples were very less as indicated by the standard deviation of density values (figure 3). Microstructural photographs (figure 4) show well-compacted grains with little amount of porosity, mostly as intragranular nature. Well-compacted cubic and cuboid-shaped periclase $(\mathrm{MgO})$ crystals are also observed at higher magnification, indicating a high purity nature of the samples.

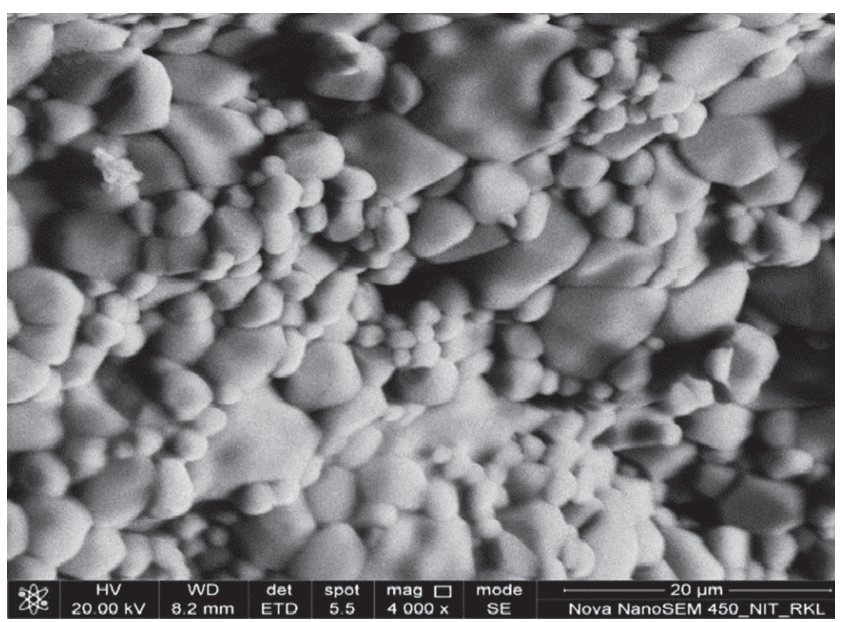

Figure 10. Scanning electron photomicrograph of the fractured surface of 2 wt $\% \mathrm{Cr}_{2} \mathrm{O}_{3}$ containing magnesia batch sintered at $1600^{\circ} \mathrm{C}$.

\subsection{Effect of $\mathrm{TiO}_{2}$ addition}

The addition of $\mathrm{TiO}_{2}$ was found to deteriorate the densification behaviour of magnesia. Higher amount of additive deteriorates in greater extent (figure 5). The addition of $\mathrm{TiO}_{2}$ might have reacted with magnesia to form intergranular magnesium titanate $\left(\mathrm{Mg}_{2} \mathrm{TiO}_{4}\right)$ and assists the grain growth, ${ }^{18,20}$ which has resulted in lower densification. Variation in the density values of each compositions were also minimum as observed from the standard deviation values (figure 5). Microstructure of the $1600^{\circ} \mathrm{C}$ sintered product containing $2 \mathrm{wt} \% \mathrm{TiO}_{2}$ shows (figure 6) non-uniform grains distributed in a scattered manner, indicating considerable growth for few grains. A porous structure is observed with large extent of intragranular porosity. Less compact grains with porosities in between has resulted in poor densification of the batch. Elemental distribution of the components is shown in figure 7 . It shows well-distributed presence of $\mathrm{Ti}$ ions in the matrix of sintered $\mathrm{MgO}$ and $\mathrm{Ti}$ is mainly present in between the $\mathrm{MgO}$ grains.

\subsection{Effect of $\mathrm{Cr}_{2} \mathrm{O}_{3}$ addition}

The addition of $1 \mathrm{wt} \% \mathrm{Cr}_{2} \mathrm{O}_{3}$ has resulted in (figure 8) an increase in density values compared to no additive batch, but further addition was found to reduce the density values. Secondary phase, like magnesium chromate formation at the grain boundaries, might have helped in increasing the densification. ${ }^{19}$ Well, compact grains with uniform grain structure were observed for $1 \mathrm{wt} \% \mathrm{Cr}_{2} \mathrm{O}_{3}$ containing batch sintered at $1600^{\circ} \mathrm{C}$ (figure 9). But an increase in $\mathrm{Cr}_{2} \mathrm{O}_{3}$ content to $2 \mathrm{wt} \%$ has resulted in some abnormal grain growth in the compacts, showing non-uniform size of grains and they are distributed in a scattered manner (figure 10). This nonuniform growth of some grains has negatively affected the density values. Standard deviation values (figure 5) of density of different compositions were low indicating minimum variation. Elemental distribution study shows (figure 11) 

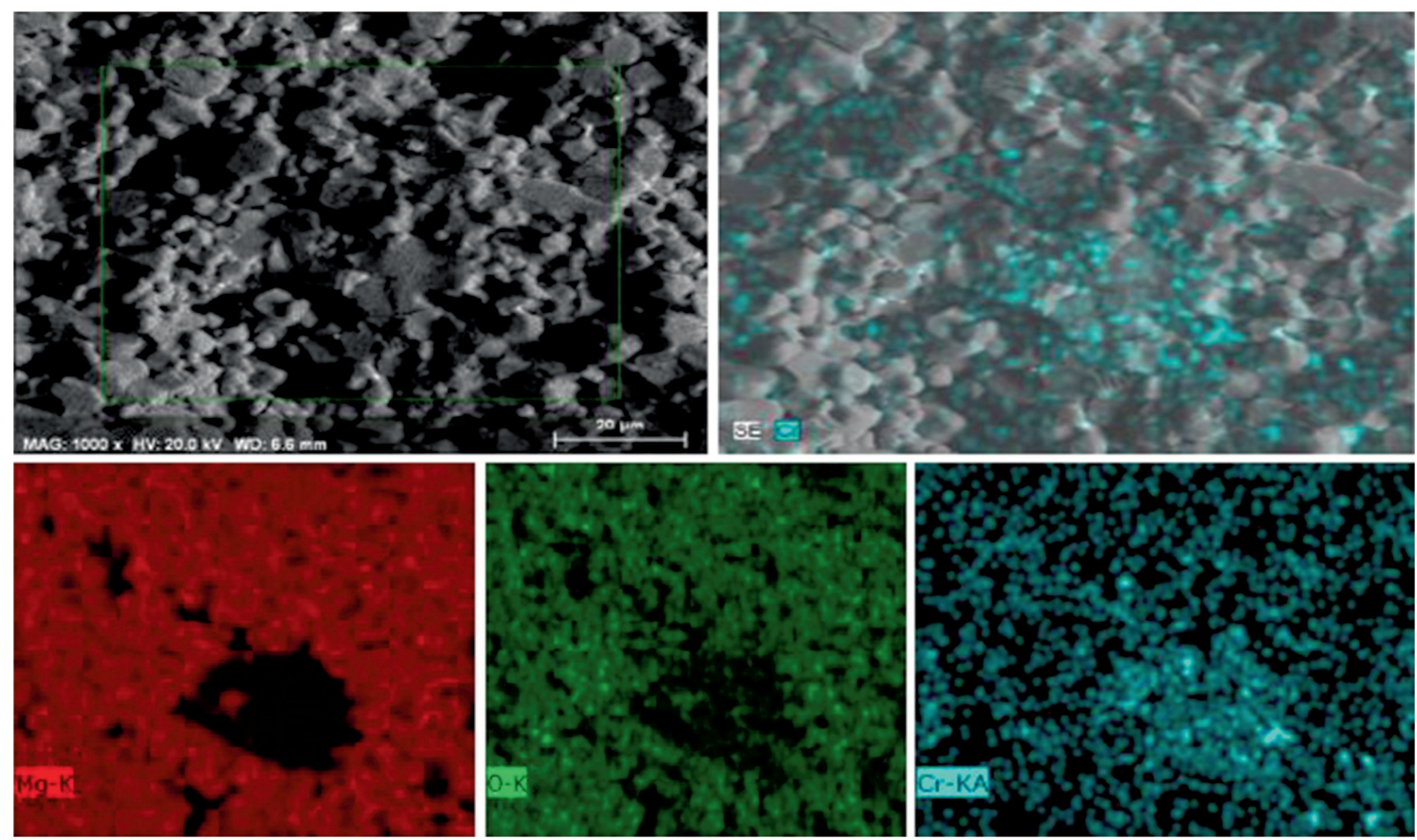

Figure 11. Elemental mapping photomicrograph of $2 \mathrm{wt} \% \mathrm{Cr}_{2} \mathrm{O}_{3}$ containing $\mathrm{MgO}$ sintered at $1600^{\circ} \mathrm{C}$.

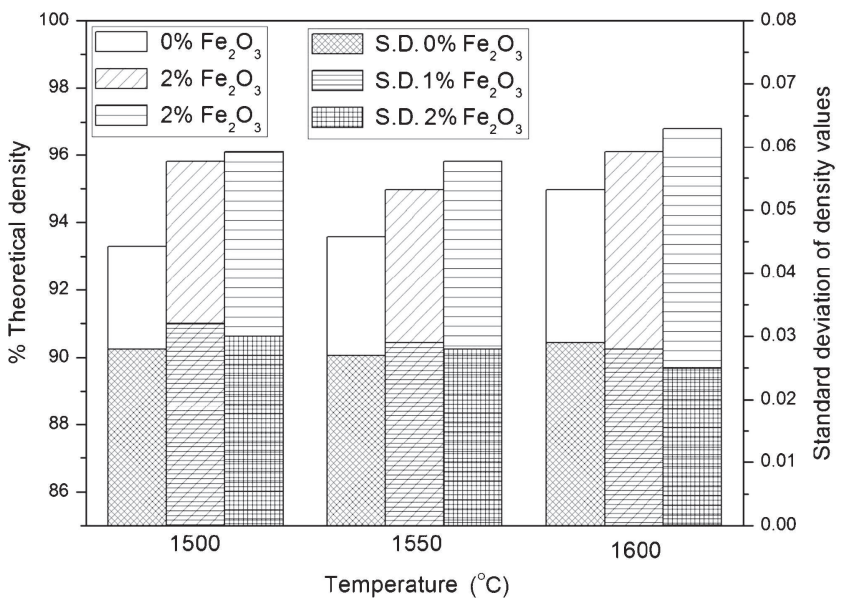

Figure 12. Variation in density and standard deviation of density values of $\mathrm{MgO}$ containing $\mathrm{Fe}_{2} \mathrm{O}_{3}$ additives.

nearly uniform and well distribution of additive $\mathrm{Cr}$ ions all through the $\mathrm{MgO}$ matrix, and $\mathrm{Cr}$ ions are mainly present in between the $\mathrm{MgO}$ grains.

\subsection{Effect of $\mathrm{Fe}_{2} \mathrm{O}_{3}$ addition}

The addition of $\mathrm{Fe}_{2} \mathrm{O}_{3}$ up to $2 \mathrm{wt} \%$ in $\mathrm{MgO}$ showed a continuous increase in density values (figure 12). The formation of magnesium ferrite at the grain boundaries might have helped in increasing the sintering and densification of magnesia, as also observed by Chaudhuri and others. ${ }^{22}$ Dense and compact microstructure was observed for the $1600^{\circ} \mathrm{C}$ sintered $2 \mathrm{wt} \% \mathrm{Fe}_{2} \mathrm{O}_{3}$ containing batch (figure 13). Little amount of intragranular porosity is also observed. In elemental distribution, $\mathrm{Fe}$ ion was found to be well distributed in the $\mathrm{MgO}$

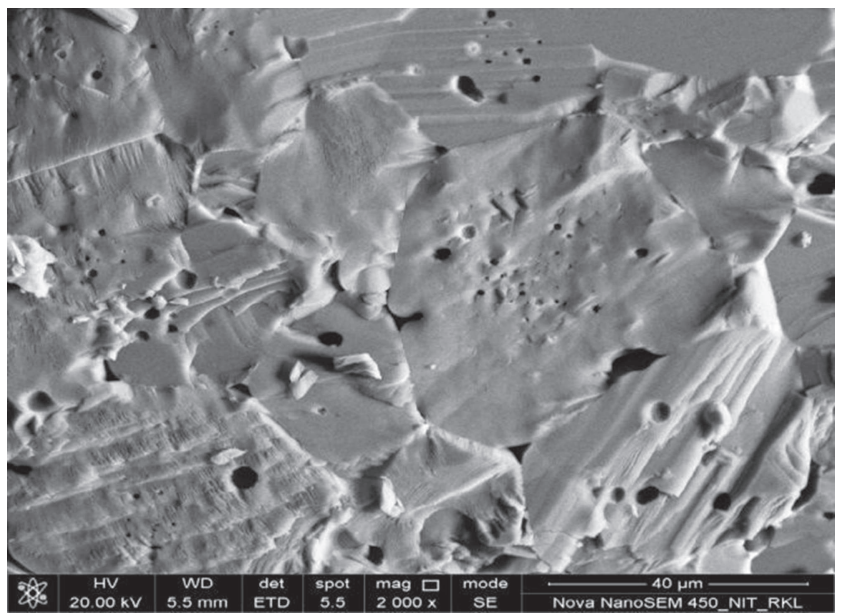

Figure 13. Scanning electron photomicrograph of the fractured surface of 2 wt $\% \mathrm{Fe}_{2} \mathrm{O}_{3}$ containing magnesia batch sintered at $1600^{\circ} \mathrm{C}$.

matrix, mainly in between the $\mathrm{MgO}$ grains (figure 14). Again the standard deviation values (figure 5) of density of different compositions were also found to be low.

\section{Conclusion}

Density of the pure magnesia was found to increase with the increase in the sintering temperature and a maximum density value of $3.4 \mathrm{~g} \mathrm{~cm}^{-3}$, i.e., is near about $93.972 \%$ of theoretical density was obtained at $1600^{\circ} \mathrm{C}$. $\mathrm{Fe}_{2} \mathrm{O}_{3}$ was found to improve the densification with very well compact and nearly uniform grain structure. $\mathrm{TiO}_{2}$ was found to deteriorate densification 

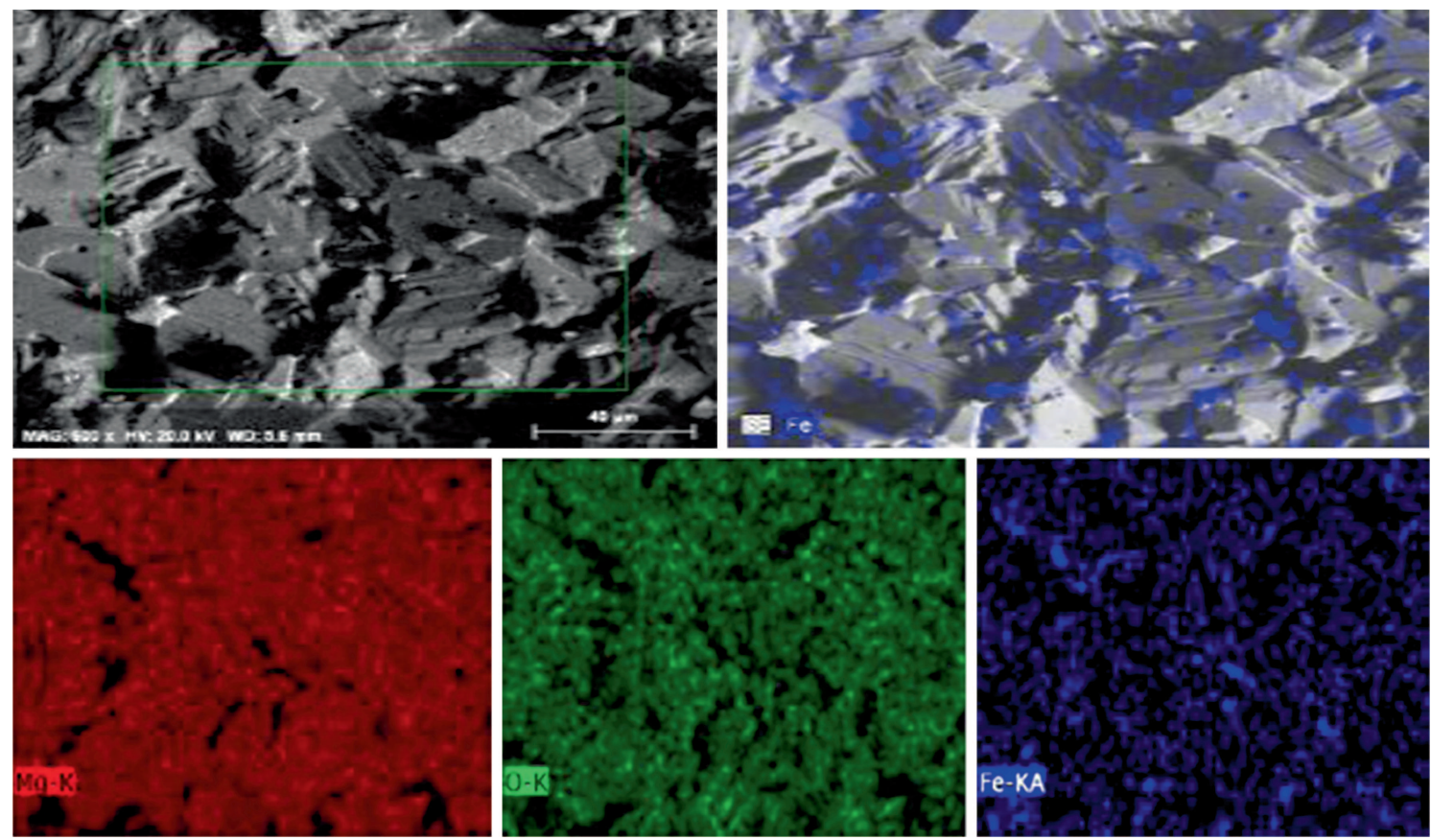

Figure 14. Elemental mapping photomicrograph of $2 \mathrm{wt} \% \mathrm{Fe}_{2} \mathrm{O}_{3}$ containing $\mathrm{MgO}$ sintered at $1600^{\circ} \mathrm{C}$.

due to grain growth. The addition of $\mathrm{Cr}_{2} \mathrm{O}_{3}$ at $1 \mathrm{wt} \%$ has improved densification but at higher amount, grain growth was observed with a reduced densification. Elemental distribution shows nearly uniform distribution of the additive ions all through the magnesia matrix. Again the standard deviation of density value was found to be very minimum $(<0.03)$ which confirms minimum variation of the density values of individual samples in each composition.

\section{Acknowledgements}

We thankfully acknowledge the support of Mr S Chakraborty for microstructural studies and other staffs of Department of Ceramic Engineering, NIT, Rourkela, for different experimentation of the study.

\section{References}

1. Layden G K and Maquarrie M 1959 J. Am. Ceram. Soc. 4289

2. Budworth D 1970 Mineral. Mag. 37833

3. Chiang Y M, Birniand D and Kingery W 1996 Physical ceramics: principles for ceramic science and engineering (John Wiley \& Sons) Chapter 5, p 392

4. Das K, Mukherjee S, Maiti P and Pal P 2010 Bull. Mater. Sci. 33439

5. Petric N, Petric B, Martinac V, Bogdanic N, MirosevicAnzulovic M and Labor M 1994 J. Eur. Ceram. Soc. 13 545

6. Matsumoto T and Kato A 1990 Ceram. Int. 16325

7. Hamano K, Nakagawa Z E and Watanabe H 1984 Advances in ceramics (ed.) W D Kingery (Columbus, Ohio: The American Ceramic Society) Vol 10, 2nd ed, p 610
8. Martinac V, Labor M and Petric N 1996 Mater. Chem. Phys. 4623

9. Zhang B, Wang Z, Zhang S, Wang X and Xu Z 2008 Key Eng. Mater. 368-372 1158

10. Nelson J W and Cutler I B 1958 J. Am. Ceram. Soc. 41406

11. Petric N, Petric B, Mirosevic-Anzulovic M and Bogdanic N 1988 Ceram. Forum Int. 657

12. Lucion T, Duvigneaud P H, Laudet A, Stenger J F and Gueguen E 2004 Key Eng. Mater. 264-268 209

13. Atlas L 1957 J. Am. Ceram. Soc. 40196

14. Allison A G, Sesler E C and Duck W H 1956 J. Am. Ceram. Soc. 39151

15. Liu J H et al 2014 Sci. China Technol. Sci. 571085

16. Liu J et al 2014 J. Eur. Ceram. Soc. 343095

17. Weyl W A 1952 Ceram. Age 6028

18. Tacvorian S 1954 Bull. Soc. France Ceram. 235

19. Austin L W, Hicks J C and Rick C A 1949 Catalytic crystallization of magnesium oxide, US Patent 2487290

20. Han B, Li Y, Guo C, Li N and Chen F 2007 Ceram. Int. 33 1563

21. Huang Q Z et al 2013 Appl. Mech. Mater. 45511

22. Chaudhuri M, Banerjee G, Kumar A and Sarkar S L $1999 \mathrm{~J}$. Mater. Sci. 345821

23. Lee Y B, Park H C, Oh K D and Riley F L 1998 J. Mater. Sci. 334321

24. Huang Q-Z 2013 Met. Mater. Trans. B 44344

25. Zargar H R, Oprea C, Oprea G and Troczynski T 2012 Ceram. Int. 336235

26. Shanaon R D 1974 Acta Crystallogr. A32 751 (from Handbook of chemistry and physics (Boca Raton, FL: CRC Press) 74th ed)

27. Ionic radius-Wikipedia, the free encyclopedia, Effective ionic radii in pico-meter of elements in function of ionic charge 